\title{
Adsorption of small molecules on gold single crystal surfaces
}

Sónia A.C. Carabineiro ${ }^{1}$, Bernard E. Nieuwenhuys² www.goldbulletin.org

\begin{abstract}
Much more work has been carried out on supported gold catalysts (also called "real" catalysts) than on gold single crystal surfaces. However, for fundamental understanding of catalysis by gold, well-defined gold surfaces and controlled conditions using the surface science approach may provide useful information concerning reaction mechanisms and the nature of active centers. This paper presents a brief overview on the work carried out regarding adsorption of several small molecules on gold surfaces from 2004, date of the last review on gold surface science [R. Meyer, C. Lemire, S.K. Shaikhutdinov and H. Freund, Gold Bull., 2004, 37, 72], until recently. Both experimental and theoretical results are discussed. A large difference between the flat $\mathrm{Au}(111)$, by far the most studied surface, and stepped/kinked surfaces, is found, demonstrating the importance of low-coordinated Au atoms for high catalytic activity.
\end{abstract}

\section{Introduction}

Supported nanogold catalysts, also called "real" catalysts, have received comparatively much more attention than gold single crystal surfaces, as they are thought to have more viable commercial applications [1-5]. However, the study of gold single crystal surfaces using the surface science approach is very important as it provides useful fundamental information relevant to reaction mechanisms and the nature of active centers of supported gold catalysts.

In 2004, a comprehensive review was published by Hans-Joachim Freund and co-workers on "surface chemistry of catalysis by gold" [6]. The present article presents a short overview on adsorption of small molecules (namely $\mathrm{CO}, \mathrm{H}_{2}, \mathrm{O}_{2}, \mathrm{NO}, \mathrm{NH}_{3}$, etc) on gold single crystal surfaces, from 2004 until recently. Both experimental and theoretical results are discussed. In addition, recent results regarding adsorption of these molecules on unsupported gold clusters are briefly discussed. Adsorption of more complex molecules demands a separate review and will not be presented in this paper. Reactions on $\mathrm{Au}$ single crystal surfaces (namely oxidation of $\mathrm{CO}$, $\mathrm{NH}_{3}$, alcohols and hydrocarbons) carried out since the last review of 2004, will be a subject of another review [7]. For general reviews on gold catalysis we refer to $[3,5-6]$.

\section{Oxygen adsorption}

Gold single-crystal surfaces do not measurably chemisorb oxygen either molecularly or dissociatively under UHV conditions or at elevated temperature and pressure [8]. Since the dissociation probability for $\mathrm{O}_{2}$ is low on gold single-crystal surfaces, other methods to obtain O-covered Au surfaces under UHV conditions have been developed, such as exposure to ozone $\left(\mathrm{O}_{3}\right)$, thermal dissociation of gaseous $\mathrm{O}_{2}$ using hot filaments, reactive ion sputtering with $\mathrm{O}_{2}^{+}$, etc [8-9].

\footnotetext{
Laboratory of Catalysis and Materials, Associate Laboratory LSRE/LCM, Department of Chemical Engineering, Faculty of Engineering, University of Porto, Rua Dr. Roberto Frias, s/n, 4200-465 Porto, Portugal

${ }^{2}$ Leiden Institute of Chemistry, Leiden University, Einsteinweg 55, 2333 CC Leiden, The Netherlands, and Schuit Institute of Catalysis, Eindhoven University of Technology, P.O. Box 513, 5600 MB Eindhoven, the Netherlands
} 
Figure 1

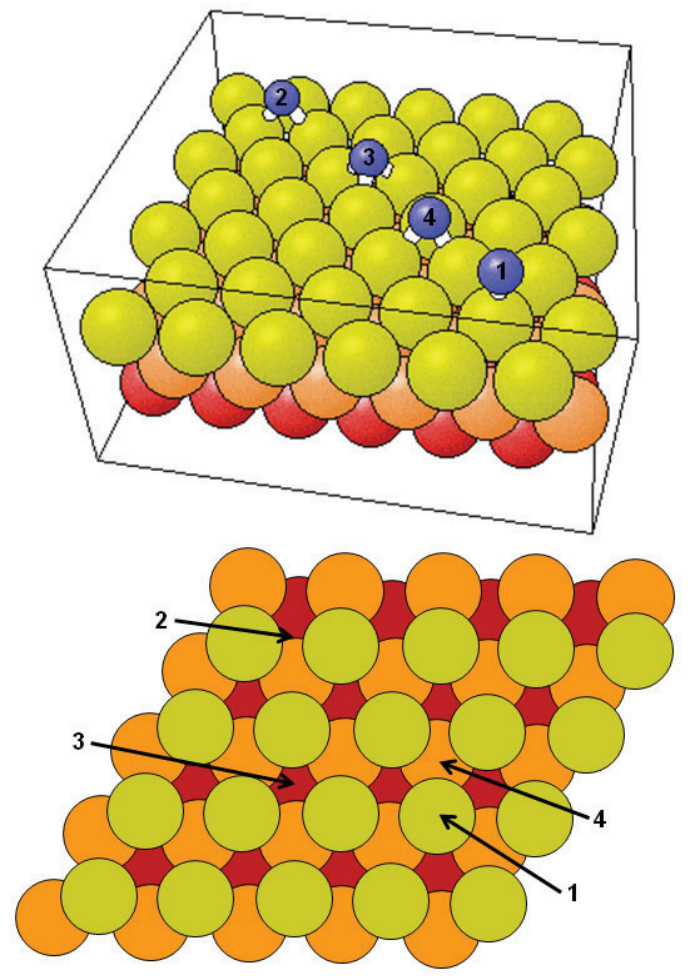

The structure of the flat non-reconstructed Au(111) surface (adapted from the NIST Surface Structure Database [10]). The yellow spheres represent the 1st layer of atoms, the orange and red spheres the 2 nd and $3 r d$ layer atoms. The common adsorption sites are 1) top sites, 2) bridge or 2-fold sites, 3) 3 -fold fcc hollow sites where a 2nd layer atom below the site is missing, and 4) 3-fold hcp hollow site with a 2nd layer atom below the surface

By far the most studied surface is Au(111) (Figure 1). Gold is the only fcc metal for which the most densely packed surface, the (111) surface, reconstructs under UHV conditions [6, 11-12].

Friend and co-workers $[9,11,13]$ found that this so-called herringbone reconstruction lifts when $\mathrm{O}$ (or S) are deposited on the surface. This lifting of the reconstruction was accompanied by the release of gold atoms from the herringbone structure. At high coverage, clusters of gold oxides (or sulfides) form by abstraction of gold atoms from regular terrace sites of the surface. Concomitant with the restructuring is the release of gold atoms from the herringbone structure to produce a higher density of low-coordinated Au sites by forming serrated step edges or small gold islands.
Gibson and Sibener [12] investigated changes in the surface structure of reconstructed $\mathrm{Au}(111)$ when small quantities of $\mathrm{O}$ atoms are adsorbed, randomly, using $\mathrm{O}\left({ }^{3} \mathrm{P}\right)$ produced from a radio frequency beam source and He diffraction to measure the structural changes. The surface reverts to the (111) structure. For much less than $0.1 \mathrm{ML}$ of $\mathrm{O}$ adsorbed at 200 $\mathrm{K}$, the $\mathrm{He}$ diffraction spectra indicate that this deconstruction is only partially complete, and the surface quickly returns to the totally reconstructed structure upon heating to room temperature. This is probably caused by the $\mathrm{O}$ diffusing away from the terraces and becoming trapped at steps or defects.

The experimental studies of Koel and co-workers [14] studied the adsorption of $\mathrm{O}_{2}$ and $\mathrm{O}_{3}$ on an $\mathrm{Au}(211)$ stepped surface (Figure 2). This surface can be described as a step-terrace structure consisting of three-atom-wide terraces of (111) orientation and a monatomic step with a (100) orientation, or 3(111) $x(100)$ in microfacet notation. Molecular oxygen $\left(\mathrm{O}_{2}\right)$ does not dissociate to produce oxygen adatoms even not under high-pressure (700 Torr) conditions with the sample at 300-450 K. Step sites do bind oxygen adatoms more tightly than do terrace sites, and this was probed by using temperature programmed desorption (TPD) of $\mathrm{O}_{2}$ following ozone exposure to produce oxygen adatoms The desorption activation energy, for the step-adsorbed oxygen was estimated to be of $142 \mathrm{kJmol}^{-1}$ and that for oxygen at the terraces near saturation coverage of $138 \mathrm{kJmol}^{-1}$, values that are similar to others reported on Au surfaces. For example, Gong and Mullins [8] reported for Au(111) an activation energy of desorption between 126 to $134 \mathrm{kJmol}^{-1}$ depending on the $\mathrm{O}$ coverage. Thus $\mathrm{Au}(211)$ does not appear to be significantly different from that on the flat $\mathrm{Au}(111)$ surface, contrary to theoretical calculations [15].

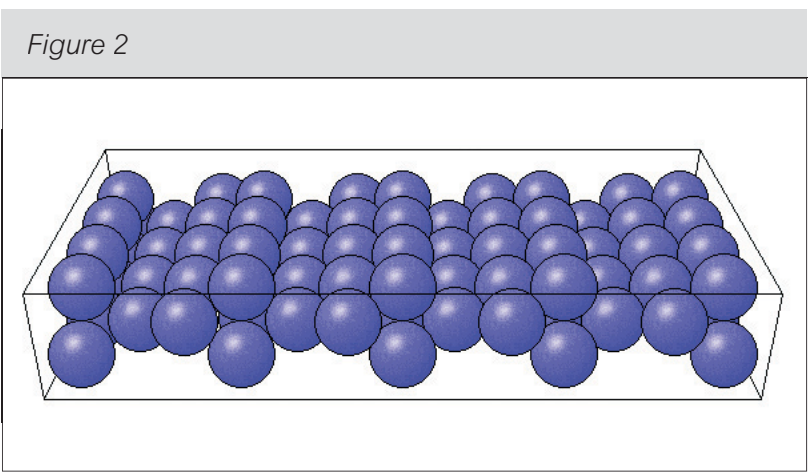

Surface structure of the Au(211) surface (generated with Surface Explorer [16]) 
Nakamura et al [17] also studied $\mathrm{O}_{3}$ dissociation on various gold single crystal surfaces, namely $\mathrm{Au}(110)$, (111) and (311). Dissociation of $\mathrm{O}_{3}$ proceeded selectively on the $A u(111)$ surface. Atomic oxygen adsorbed only on the (111) terraces of $\mathrm{Au}(311)$, whereas no dissociation occurred on the $\mathrm{Au}(100)$ steps on this surface, indicating that $\mathrm{O}_{3}$ dissociation on gold strongly depends on the structure of the gold sites.

Vinod et al. [18] showed that $\mathrm{O}_{2}$ did not adsorb on $\mathrm{Au}(310)$. Apparently, the presence of steps is not sufficient to enable adsorption under the experimental conditions used.

Friend and co-workers [23] showed that the dissociation probability of $\mathrm{O}_{2}$ on the reconstructed $\mathrm{Au}(111)$-herringbone surface is increased by three orders of magnitude by the presence of some atomic oxygen on the surface. Specifically, at $400 \mathrm{~K}$ the dissociation probability of $\mathrm{O}_{2}$ on oxygen precovered $\mathrm{Au}(111)$ is on the order of $10^{-3}$, whereas there is no measurable dissociation on clean Au(111), establishing an upper bound for the dissociation probability of $10^{-6}$.

Baker et al. [19] used Density Functional Theory (DFT) calculations to study the effects of $\mathrm{O}$ (and $\mathrm{Cl}$ ) coverage on the atomic structure of the $\mathrm{Au}(111)$ surface and found that the release and incorporation of gold atoms in the adsorbate layer become energetically favorable only at high coverages of either $\mathrm{O}$ or $\mathrm{Cl}$ (>0.66 $\mathrm{ML}$ (monolayer) for $\mathrm{O}$ ) whereas adsorption without the incorporation of gold is favorable at lower coverages. The bonding between the adsorbate and gold substrate changes significantly with coverage, becoming more covalent (less ionic) at higher $\mathrm{O}$ (or $\mathrm{Cl}$ ) coverage.

They also used DFT to study the adsorption of atomic oxygen on $\mathrm{Au}(111)$ surfaces containing defects such as vacancies and steps [20]. They found that there is an attractive interaction between oxygen atoms and vacancies on the surface, which lowers the energy to create a surface vacancy by $19 \mathrm{kJmol}^{-1}$, but the interaction between oxygen and gold adatoms is repulsive. Oxygen atoms prefer the fcc hollow sites on $\mathrm{Au}(111)$ [20-22].

German and Efremenko [23] calculated by DFT the activation energy of oxygen dissociative adsorption on $\mathrm{Au}(111)$ to be $178 \mathrm{kJmol}^{-1}$, which is in agreement with experimental results $\left(134-142 \mathrm{kJmol}^{-1}\right)$ [24].

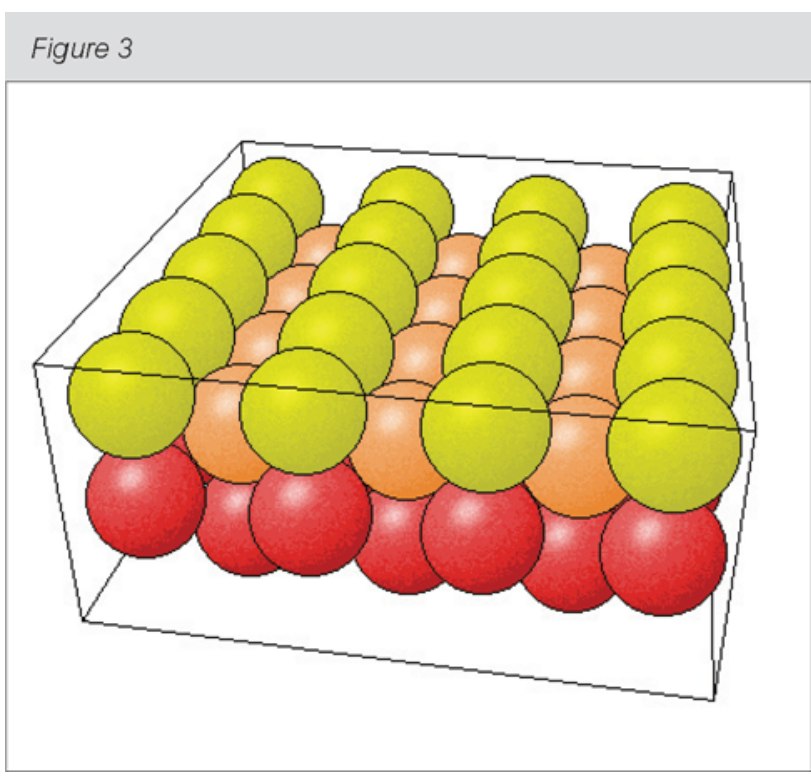

Surface structure of the Au(110) surface (adapted from the NIST Surface Structure Database [10]). The yellow spheres represent the 1st layer of atoms, the orange and red spheres the 2 nd and 3rd layer atoms

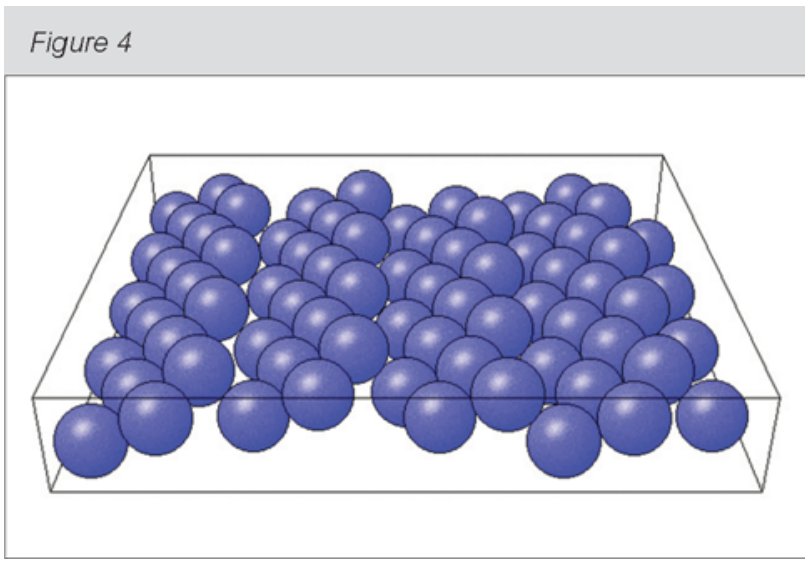

Surface structure of the Au(321) surface (generated with Surface Explorer [16])

Shi and Stampfl [25] also performed DFT calculations to investigate the adsorption of oxygen on the $\mathrm{Au}(111)$ surface, including on-surface, subsurface, and surface oxide formation. They found that atomic oxygen adsorbs weakly on the surface and is barely stable with respect to molecular oxygen, while pure subsurface adsorption is only metastable. Interestingly, the most favorable structure investigated involves a thin surface-oxidelike configuration, where the oxygen atoms are quasi threefold-coordinated to gold atoms, and the gold atoms of the surface layer are twofold, linearly coordinated to oxygen atoms. By including the effect 
of temperature and oxygen pressure they also found that this configuration is the most stable for realistic catalytic temperatures and pressures, e.g., for lowtemperature oxidation reactions, and is predicted to be stable up to temperatures of around $420 \mathrm{~K}$ at atmospheric pressure.

Torres et al. [26] employed periodic slab model calculations to examine the charge state of atomic oxygen species adsorbed on Cu(111), Ag(111) and $\mathrm{Au}(111)$ surfaces. Threefold fcc sites are computed to be preferred on all three substrates. In agreement with the metal electronegativity values, large negative charge of similar size is found on oxygen in the $\mathrm{O} /$ $\mathrm{Cu}(111)$ and $\mathrm{O} / \mathrm{Ag}(111)$ systems, whereas $\mathrm{O}$ on $\mathrm{Au}(111)$ is significantly less ionic.

Miller and Kitchi [27-28] used DFT calculations to study adsorption of oxygen on $\mathrm{Au}$ and Pt (111) surfaces. They found a nearly linear coverage dependence for the calculated adsorption energies of the most stable configurations for atomic oxygen on both surfaces [28].

DFT have been used by Landmann et al. [2930] to study the adsorption of atomic oxygen on the $\mathrm{Au}(110)$ surface (Figure 3). The stability of oxygen adstructures on various (1xr) "missing row" reconstructions of the clean $\mathrm{Au}(110)$ surface was investigated. Three Au-O chainlike structures have been identified to be especially stable and are clearly favored over oxygen conglomerates on the $(1 \times r)$ surfaces and represent the most stable form of chemisorbed atomic oxygen on Au(110) surfaces [30]. The surface energies of the clean reconstructed surfaces are found to be very close with an energy minimum for $\mathrm{Au}(110)-(1 \times 3)$ [29].

Gomes and co-workers [31] used DFT calculations to investigate the interaction of atomic and molecular oxygen on the $\mathrm{Au}(321)$ surface (Figure 4). It was found that the atoms prefer interaction with surface cavities, while in the case of molecules, adsorption is more favorable if the molecular axis is parallel to the surface terraces on bridge or nearby bridge sites. The most favorable reaction path is that starting from the preferred adsorption configuration for the oxygen molecule, i.e., a bridge site at the edge of the terrace, and involves a previous rotation of the molecular axis, and one of the oxygen atoms is almost falling down to the nearby terrace and the other is holding onto the top of the step. At the end of the reaction, the oxygen atoms are adsorbed near the step but on different terraces. These results are similar to those obtained previously for the same reaction on the $A u(211)$ surface [14], showing the importance of the surface steps in the oxygen activation on gold surfaces. However, the use of the present results requires some caution since previous experimental work by Koel's group [14] showed the absence of molecular oxygen dissociation on the $\mathrm{Au}(211)$ surface even under high-pressure (700 Torr) conditions with the sample at 300-450 K. Nevertheless, both experimental and theoretical works show unequivocally that step sites do bind oxygen adatoms more tightly than do terrace sites.

Fajín et al. [32] also studied the deposition of oxygen atoms on the $\mathrm{Au}(321)$ surface by DFT. The clean and oxygen covered $A u(321)$ surfaces were modeled by a periodic supercell approach; the unit cell has 15 gold atoms, the outermost five define the (111) terrace and the step. The adsorption of a single oxygen atom is more favorable if it occurs at a fcc hollow site on the (111) terrace adjacent to the step while for the co-adsorption of two oxygen atoms on the Au(321) surface, hollow sites nearby the step are preferred. The introduction of an additional oxygen atom on the already optimized slabs containing two oxygen atoms yield, in some cases, structures with a single oxygen atom attached to the surface and an oxygen molecule far from the slab. In the other cases, several initial geometries converged to the same final structure and, in general, the adsorption of three oxygen atoms per unit cell was found to be thermodynamically unfavorable. The exception was a planar structure formed after reconstruction of the surface. The simultaneous adsorption of four oxygen atoms per unit cell is characterized by relatively high adsorption energies of -51 and $-54 \mathrm{kJmol}^{-1}$, corresponding to a porous structure containing subsurface oxygen atoms forming a gold oxide layer and to a well ordered folded structure. The addition of a fifth oxygen atom to the structures already containing four oxygen atoms on the surface resulted in an endothermic process suggesting that they will be hard to find even after exposure to high pressures of oxygen.

Okamoto [33] used the DFT approach to show that molecular $\mathrm{O}_{2}$ and atomic $\mathrm{O}$ adsorption on $\mathrm{Au}(111)$ is much weaker than on $\mathrm{Pt}(111)$ and $\mathrm{Cu}(111)$, but there is a preference for fcc sites, compared to hcp. On $\mathrm{Au}_{55}$ clusters, contrary to the site preference on the (111) surface, O atom is more stable on hcp than on fcc, which is consistent with the prediction from coordination-number counting. 
Fernández etal. [34] investigated the adsorption of $\mathrm{O}_{2}$ on neutral Au clusters, by means of DFT calculations and found out that the $\mathrm{O}_{2}$ adsorption energy shows odd-even effects, with odd $n$ clusters being more active towards oxygen than even clusters, and that $\mathrm{Au}_{6}$ and $\mathrm{Au}_{7}$ clusters are energetically favorable for dissociative adsorption.

Molina and Hammer [35] also used DFT to $\mathrm{O}_{2}$ adsorption on anionic $\mathrm{Au}_{\mathrm{n}}(\mathrm{n}=1-11)$ clusters either free or supported. They concluded that $\mathrm{O}_{2}$ adsorption is strong whenever unpaired electrons are present, except for some small, supported, planar, highband-gap clusters.

We can conclude that for $A u(111)$ the preferred adsorption site for $\mathrm{O}$ atoms is the fcc hollow site. The activation energy of desorption (in the form of $\mathrm{O}_{2}$ molecules) is of the order of $130 \mathrm{kJmol}^{-1}$. On step sites it is a little bit higher. However, $\mathrm{O}_{2}$ dissociation on Au surfaces has not been observed in experimental studies and it is a very difficult process according to DFT calculations. If adsorbed $\mathrm{O}$ is present then it greatly affects the reactivity of the gold surfaces.

\section{Hydrogen adsorption and coadsorption of $\mathrm{O}_{2}$ and $\mathrm{H}_{2}$ or $\mathrm{H}$}

Once again, $\mathrm{Au}(111)$ is the most studied surface both experimentally and computationally.

Vinod et al. [18] showed that $\mathrm{H}_{2}$ does not adsorb on $\mathrm{Au}(310)$. Apparently, just like with $\mathrm{O}_{2}$, the presence of steps is not sufficient to enable adsorption/ dissociation under the experimental conditions used.

Okamoto [33] used the DFT approach to show that atomic $H$ adsorption on $\mathrm{Au}(111)$ is much weaker than on Pt(111). The endothermic adsorption energy obtained means that $\mathrm{H}$ atoms on the $\mathrm{Au}(111)$ are less stable than free $\mathrm{H}_{2}$ molecules. The energy is also endothermic for $\mathrm{H}$ adsorption at the top of $\mathrm{Au}_{55}$ clusters, but slightly exothermic for fcc and hcp hollow sites. Because the $\mathrm{H}$ adsorption energy is a good descriptor of reactivity of $\mathrm{H}_{2}$ oxidation [34], these results may suggest that $\mathrm{Au}_{55}$ might be a good candidate for a $\mathrm{H}_{2}$ oxidation catalyst in protonexchange membrane fuel cells [33].

Barrio et al. [36] also used DFT to study the coadsorption of $\mathrm{O}_{2}$ and $\mathrm{H}_{2}$ or $\mathrm{H}$ on $\mathrm{Au}(111)$ and $\mathrm{Au}(100)$. For the adsorption of isolated $\mathrm{O}_{2}$, no significant interaction was obtained between the flat metal surfaces and the oxygen molecule. With the presence of predissociated hydrogen on a gold system, the adsorption energy of oxygen is much higher in absolute value than for the $\mathrm{O}_{2} / \mathrm{Au}$ systems, accompanied by the formation of a hydroperoxo species. The origin of the synergistic effect observed for the coadsorption of hydrogen and $\mathrm{O}_{2}$ is the formation of $\mathrm{O}-\mathrm{H}$ bonds that enhances the $\mathrm{O}-\mathrm{Au}$ interactions, reducing the $\mathrm{O}-\mathrm{Au}$ bond lengths (0.15-0.30 Angstroms).

\section{Carbon monoxide adsorption on clean and $O$ precovered surfaces}

The two CO thermal desorption peaks that have been observed in a number of experimental studies have been assigned to $\mathrm{CO}$ adsorbed on defect sites, such as edges and corner sites, which contain 7- and 6-fold coordinated Au atoms [5-7]. Gottfried et al. [37] reported that additional high temperature CO desorption peaks appear after sputtering an $\mathrm{Au}(110)$ surface, indicating that $\mathrm{CO}$ adsorbs more strongly on defects, i.e. atoms with a coordination number $<7$. In these studies the exact nature and concentration of the low-coordinated sites were not well defined, as they were created by sputtering.

Adsorption of $\mathrm{CO}$ at $100 \mathrm{~K}$ has been reported for $A u(100), A u(110), A u(211)$ and $A u(332)$, as reviewed by Meyer et al. [6] and more recently by Kim et al. [38].

Recently, Weststrate et al. [39] used a combination of synchrotron-based high resolution core level photoemission spectroscopy (HRCLS) and thermal desorption spectroscopy to investigate the adsorption of $\mathrm{CO}$ on two vicinal single crystal $\mathrm{Au}$

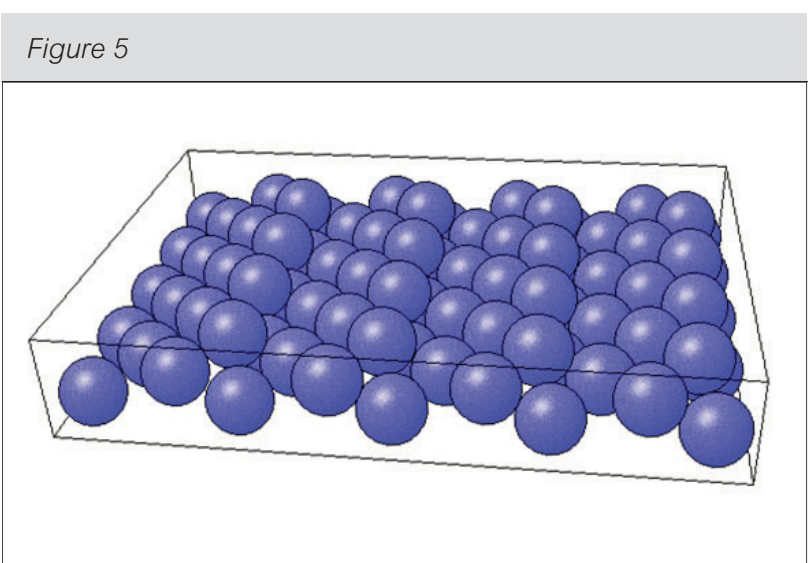

Surface structure of the Au(310) surface (generated with Surface Explorer [16]) 
surfaces which differ in the structure of their terraces: the (321) surface has terraces with a (111)-like structure (Figure 4), whereas the terraces of the (310) surface have a (100)-like structure (Figure 5). The step atoms of both surfaces have a coordination number of 6 , while the terraces contain both 8 and 9-coordinated atoms. As can be seen in Figure 6, the $\mathrm{Au}(321)$ contains five different types of surface atoms, while the $\mathrm{Au}(310)$ surface contains only three different types.

The CO adsorption behavior was found to be very similar for both surfaces. Three different desorption peaks due to chemisorbed $\mathrm{CO}$ were identified, which desorb around $100 \mathrm{~K}(\alpha), 120 \mathrm{~K}(\beta)$ and 180 $K(\gamma)$, respectively. A fourth, weakly bound state was identified below $90 \mathrm{~K}$ which appears as a single peak in both the $\mathrm{C} 1 \mathrm{~s}$ and $\mathrm{O} 1 \mathrm{~s}$ spectral regions. These results indicate that $\mathrm{CO}$ only adsorbs on the step atoms under the experimental conditions used. The different desorption peaks are explained by substrate-mediated long-range interactions between the adsorbates. Comparison with literature results showed that the $\mathrm{CO}$ adsorption energy is not only dependent on the coordination number of the $\mathrm{Au}$ atoms, but that the exact geometrical structure of the surface also plays a role.

Piccolo et al. [40] studied the adsorption of $\mathrm{CO}$ on $\mathrm{Au}(111)$ in the $10^{-3}-10^{3}$ Torr range at room temperature. Using scanning tunneling microscopy (STM), a CO-induced modification of the surface morphology (step edge roughening) and terrace structure $(22 \times \sqrt{3} \rightarrow 1 \times 1$ transition) is evidenced. Reflection absorption infrared spectroscopy experiments suggest that CO molecules are linearly chemisorbed on top of gold atoms and that adsorption occurs only above $\sim 1$ Torr CO pressure at room temperature. The large effect of the surface structure on the $\mathrm{CO}$ heat of adsorption is nicely illustrated by the fact that at room temperature a $\mathrm{CO}$ pressure of 1 or 2 orders of magnitude higher is needed for $\mathrm{CO}$ adsorption on $\mathrm{Au}(111)$ than on $\mathrm{Au}(110)$, with $\mathrm{CO}$ stretching frequencies at, respectively, 2110 and $2060 \mathrm{~cm}^{-1}$ [40]. DFT calculations, through consideration of perfect, stepped (221 and 311) or kinked (874) surfaces support these results and give additional evidence of strong structure sensitivity for $\mathrm{CO}$ adsorption on gold.

\section{Figure 6}

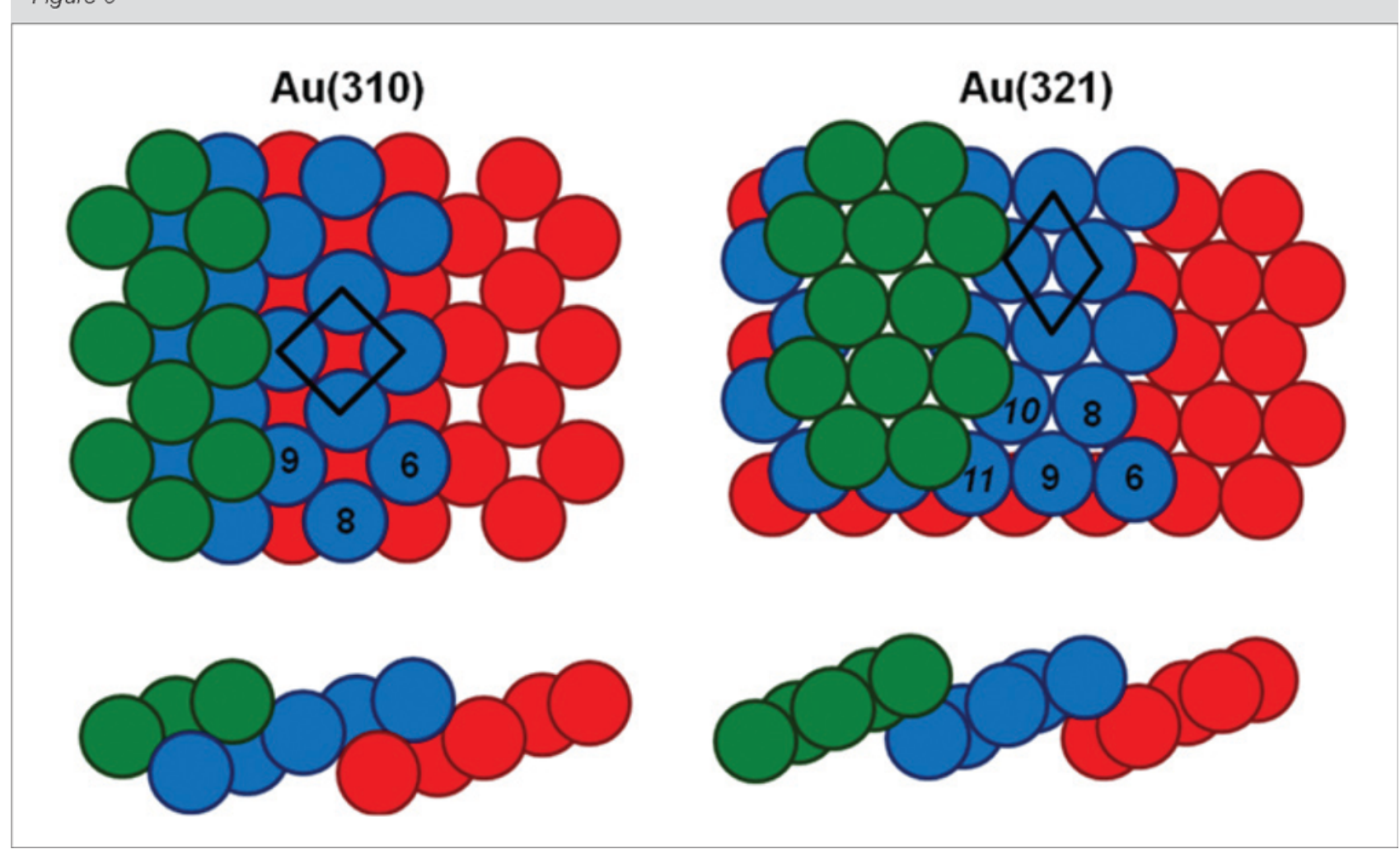

Top and side view of the $A u(310)$ and $A u(321)$ surfaces. The coordination number for the different types of surface atoms is indicated in the Figure (adapted from ref. [39]) 
Pierce et al. [41] reported the CO-induced lifting of the hexagonal surface reconstruction on $\mathrm{Au}(100)$ at a higher pressure than that studied previously by Rienks et al. for $\mathrm{CO}$ and NO adsorption [42] (see appropriate section below).

Cadete Santos Aires et al. studied the effect of the CO pressure on the structure of the Au(110) surface [43]. These authors had already investigated the adsorption of $\mathrm{CO}$ on $\mathrm{Au}(110)$, by STM at high pressures (1-500 Torr) [44] and in their recent study [43] they presented results concerning the first steps of the modification of $\mathrm{Au}(110)$ surface at intermediate pressures (0.001-1 Torr). In this way, a rather comprehensive view of the evolution of the surface structure of $\mathrm{Au}(110)$ from $10^{-9}$ to 500 Torr was obtained. The structure and morphology of the surface changes with increasing $\mathrm{CO}$ pressure (above 0.001 Torr and up to 500 Torr): under vacuum conditions, the $\mathrm{Au}(110)$ surface exhibits a $(1 \times 2)$ reconstruction which yields aligned terraces in the [1-10] direction at a larger scale. CO chemisorption at 0.01 Torr induces a slow deconstruction of the $(1 \times 2)$ surface leading to a $(1 \times 4)$ structure under 0.1 Torr of CO. At higher pressures (0.5 to 30 Torr) a dramatic restructuring is observed where the terraces aligned in the [1-10] direction under vacuum evolve to yield atomic-high monoatomichigh islands. Their size increases with increasing $\mathrm{CO}$ pressure [9]. At 100 Torr of CO the surface exhibits a $(1 \times 1)$ unreconstructed surface prior to the new surface structure observed at 500 Torr of $\mathrm{CO}$ with $\sim 0.05 \mathrm{~nm}$ deep holes arranged in a c(4x4) array.

Koel and co-workers [38] showed that CO is only weakly adsorbed on a $\mathrm{Au}(211)$ stepped singlecrystal surface, and more strongly bound at step sites (50 $\left.\mathrm{kJmol}^{-1}\right)$ than at terrace sites (27-38 $\mathrm{kJmol}^{-1}$ ). CO was also adsorbed at atop sites at all coverages and conditions. Authors conclude that the presence of these particular step sites at the $\mathrm{Au}(211)$ surface imparts stronger $\mathrm{CO}$ bonding and a higher reactivity than on the flat $A u(111)$ surface, although the differences are not as large as for more reactive metals or other stepped Au surfaces.

Nakamura et al. [17] studied CO adsorption on $A u(110), A u(111)$ and $A u(311)$ surfaces using X-ray photoelectron spectroscopy (XPS), TPD, and polarization modulation infrared reflection absorption spectroscopy (PM-IRAS). No CO adsorption was observed at $273 \mathrm{~K}$ for any of the gold surfaces at $\mathrm{CO}$ pressures below 0.01 Torr. Two absorption bands were observed on $\mathrm{Au}(111)$ and $\mathrm{Au}(100)$ around
$2080 \mathrm{~cm}^{-1}$ at CO pressures above 0.5 Torr at 273 $\mathrm{K}$ and assigned to $\mathrm{CO}$ adsorbed on atop sites. On the other hand, the band of $\mathrm{CO}$ adsorbed on step sites was observed at $2117 \mathrm{~cm}^{-1}$ above 0.01 Torr for $\mathrm{Au}(311)$, showing that $\mathrm{CO}$ adsorbs preferentially onto the step sites of the stepped gold surface.

Bäumer and co-workers [45] performed TPD and infrared absorption spectroscopy for a whole range of $\mathrm{Au}$ surfaces. They observed two desorption states at 130-145 and 170-185 K, respectively, and one infrared absorption band at around $2120 \mathrm{~cm}^{-1}$. They also carried out theoretical studies of $\mathrm{CO}$ adsorption on $\mathrm{Au}$ (332). The calculations show that CO desorption states above $100 \mathrm{~K}$ may be related to $\mathrm{CO}$ at step-edges and not on terrace sites. Authors concluded that both desorption peaks belong to $\mathrm{CO}$ on low-coordinated Au atoms at steps and kinks. For the sputtered $A u(111)$ surface, STM reveals a rough pit-and-mound morphology with a large number of such sites. In annealing experiments they observed that the loss of these sites coincides with the loss of $\mathrm{CO}$ adsorption capacity, corroborating the conclusions.

Maksymovych and Yates [46], using STM, observed that $\mathrm{CO}$ spontaneously forms distinct and stable $(\mathrm{CO})_{n}$ clusters $(n=2-5)$ on the $A u(111)$ surface, where the $\mathrm{CO}$ molecules are adsorbed on the nearest-neighbor Au atoms. The attractive interaction underlying the cluster formation leads to the ability to manipulate the clusters without their decomposition.

Loffreda and Sautet [47] performed, through DFT calculations, a CO stretching frequency analysis for the adsorption of $\mathrm{CO}$ on various $\mathrm{Au}(110)$ surfaces: the unreconstructed $(1 \times 1)$ surface, the missing-row reconstructed $(1 \times 2)$ surface, the vicinal stepped ( $2 \overline{3} 0)$ surface, and the adsorption on adatoms deposited on the (110)-(1x2) surface. On all the surfaces, the top site is the most favorable one. The thermodynamical results show that two types of $\mathrm{CO}$ adsorption structures are competitive under UHV conditions (low pressure and temperature) but also in the high pressure regime (up to 100 Torr) at room temperature. The first structure type is $\mathrm{CO}$ adsorption along the ridges of the missing-row reconstructed surface at various coverages, and the second one is a coadsorption structure where CO adsorbs both along the ridges of the reconstruction and on gold adatoms that are located in the empty troughs. The unexpected stability of the adsorption on gold adatoms has been explained by a stronger adsorption energy which compensates the energetic 
cost of the formation of such a surface defect. The same group [48] also proposed a mechanism for the removal of the $(1 \times 2)$ missing-row reconstruction on $\mathrm{Au}(110)$ under high $\mathrm{CO}$ pressure. According to authors, elevating the pressure from ultrahigh vacuum to atmospheric pressure causes the emergence of adsorption structures containing Au-CO entities.

Henry et al. [49] performed ab initio calculations of CO adsorption energies on Au(111) (100), (211) and (532) gold surfaces (the latter is depicted in Figure 7). For (111) the lowest adsorption energy was found $\left(27 \mathrm{kJmol}^{-1}\right)$ and the energy difference for $\mathrm{CO}$ on the various sites on this surface (top, bridge, fcc and hcp hollow ) is less than $1 \mathrm{kJmol}^{-1}$. As for the (110) surface, of the three possible adsorption sites, the bridge site was found to be slightly energetically preferable over the top site with an energy difference of $4 \mathrm{kJmol}^{-1}$. The calculated adsorption energy was $37 \mathrm{kJmol}^{-1}$. For a CO molecule adsorbed on the top and bridge sites of the step edge of the (211) surface, the adsorption energy was $52 \mathrm{kJmol}^{-1}$, while for $\mathrm{CO}$ adsorbed on the Au atom at the kink site of $\mathrm{Au}(532)$, it was found to be $66 \mathrm{kJmol}^{-1}$, which is the same as for the previous surface with coordination 7 . This shows steps and kinks on the surface are beneficial for the activity.

Hussain et al. [50] used DFT to study CO adsorption on $\mathrm{Au}(111),(100),(110)$ and (310) surfaces, and on an even more corrugated surface, in which an additional gold atom has been placed on the hollow sites of a Au(100) surface (as done before by Liu et al. [48]). The adsorption energy of $\mathrm{CO}$ decreases in the order $\mathrm{Au} / \mathrm{Au}(100)>\mathrm{Au}(310)>\mathrm{Au}(110) \approx \mathrm{Au}(100)$ $>A u(111)$, supporting the view that defects, steps and kinks on the surface determine the activity. Bridge site is favored for all surfaces except Au(310), where top coordination is preferred. In all adsorption configurations, $\mathrm{C}-\mathrm{O}$ molecular axis is perpendicular to the surface.

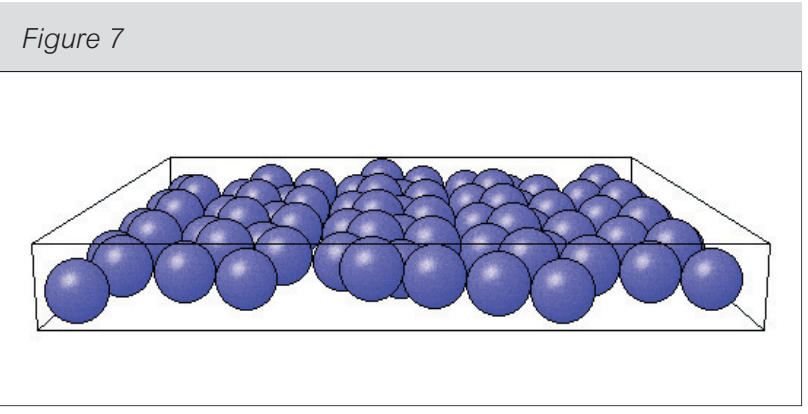

Surface structure of the Au(532) surface (generated with Surface Explorer [16])

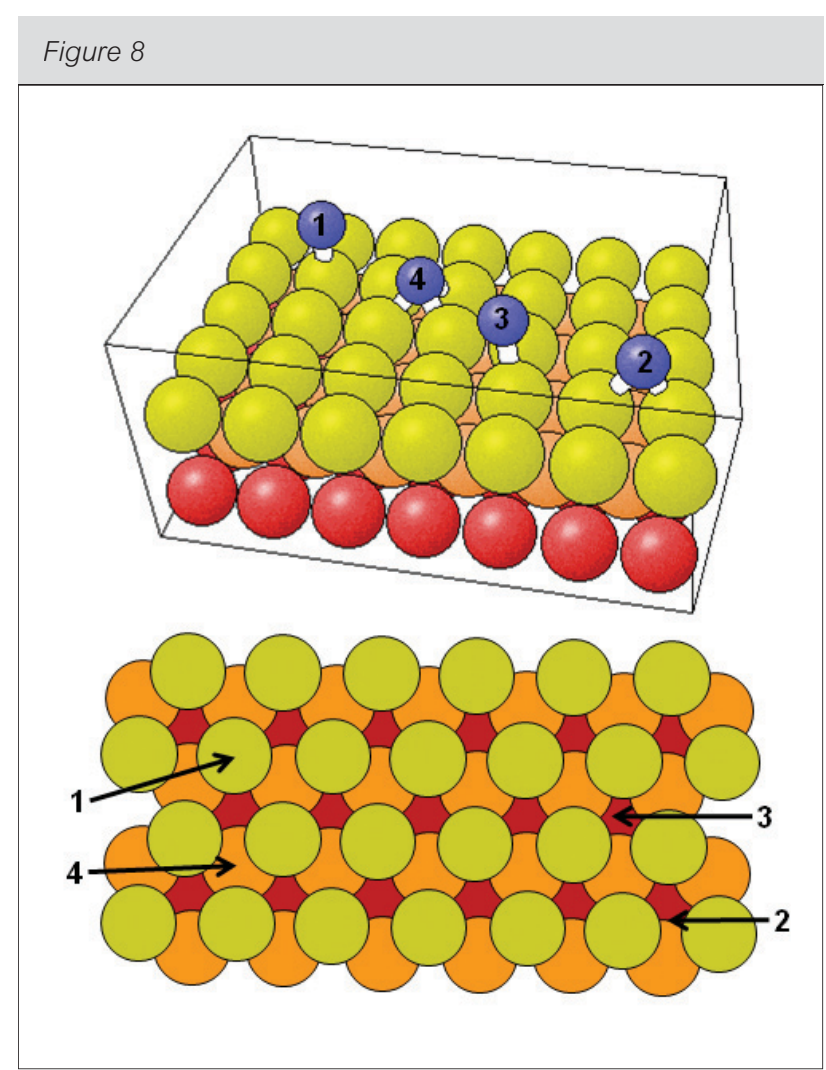

The structure of the flat non-reconstructed $A u(100)-(1 \times 1)$ surface (adapted from the NIST Surface Structure Database [10]). The common adsorption sites are 1) top sites, 2) bridge or 2-fold sites, 3) 4-fold fcc hollow sites where a 2nd layer atom below the site is missing, and 4) 4-fold hcp hollow site with a 2nd layer atom below the surface

Okamoto [33] also used the DFT approach to study the $\mathrm{CO}$ adsorption on $\mathrm{Au}(111)$ surface and on $\mathrm{Au}_{55}$ clusters. Both have low $\mathrm{CO}$ adsorption energies, when compared with Pt or $\mathrm{Cu}$.

Fernández et al. [34] investigated the adsorption of $\mathrm{CO}$ on neutral $\mathrm{Au}_{\mathrm{n}}$ clusters, by means of firstprinciples DFT calculations. The adsorption of CO occurs on top of the least coordinated $\mathrm{Au}$ atom, except for $\mathrm{Au}_{5}$ and $\mathrm{Au}_{7}$ where the bridge position is preferred. In these bridge sites, both the $\mathrm{CO}$ electronic charge and bond distance increase, whereas the vibrational frequency decreases, as compared with the values for $\mathrm{CO}$ adsorbed on top sites.

Koel and co-workers [38] created oxygen adatoms on a $\mathrm{Au}(211)$ surface using ozone exposures at 85 $\mathrm{K}$ and $300 \mathrm{~K}$, and then exposed the surface to $\mathrm{CO}$. Authors concluded that $\mathrm{CO}$ reacts with preadsorbed oxygen on the surface during its dosing since very 
little adsorbed CO was present on the surface. Only after large CO exposures, a small amount of CO was found on the surface after reacting away accessible oxygen adatoms. Thus Au(211) does not behave significantly different from the flat $\mathrm{Au}(111)$ surface [15].

We conclude from the data presented that for the flat (111) surface the adsorption energy of $\mathrm{CO}$ is very low and that there is no clear preference for a certain site. For the more open surfaces the adsorption energy is much larger and it increases with increasing unsaturation of the gold atoms involved in the bonding. $\mathrm{O}$ adatoms react easily with CO on gold surfaces.

\section{Adsorption of nitrogen oxides and effect of preadsorbed 0}

As reviewed by Freund and co-workers [6], Koel's group observed no NO adsorption on Au(111) down to a temperature of $\sim 95 \mathrm{~K}$ [51]. However, later, Mullins's group [52] obtained some contradictory results, by observing a thermal desorption peak at $\sim 150 \mathrm{~K}$, which corresponds to an adsorption energy of approximately $39 \mathrm{kJmol}^{-1}$. They speculated that the contradiction is due to the differences in the concentration of surface defects and steps present on the surfaces.

Using variable temperature STM, Rienks et al. [42] have observed the lifting of the $\mathrm{Au}(100)$ hex surface reconstruction after NO exposure. This NO adsorption-induced hex $\rightarrow(1 \times 1)$ phase transition (Figure 8) was observed only around $170 \mathrm{~K}$, which suggests that the process is slightly activated. Under the same conditions, $\mathrm{CO}$ and $\mathrm{O}_{2}$ cannot drive the phase transition, indicating weaker interaction. Thermal desorption spectroscopy experiments provide an estimate of the strength of $\mathrm{NO}$ chemisorption on $\mathrm{Au}(100)$ of $57 \pm 4 \mathrm{kJmol}^{-1}$ [42]. The desorption spectrum after saturation with $\mathrm{NO}$ at $170 \mathrm{~K}$ is given in Figure 9 the complexity of the spectrum can be explained by several features: different adsorption sites due to the formation of the gold adislands, lateral interactions between the adsorbed NO molecules can alter the appearance of the desorption spectrum and, finally, a restructuring of the surface takes place during the temperature ramp.

Vinod et al. [18] showed that $\mathrm{N}_{2}$ did not adsorb on $\mathrm{Au}(310)$. On the other hand, $\mathrm{NO}$ and $\mathrm{N}_{2} \mathrm{O}$ were found to adsorb fairly well on the same surface as shown by XPS and TPD experiments. Interestingly, NO was found to decompose on $\mathrm{Au}(310)$ at temperatures as low as $80 \mathrm{~K}$, forming $\mathrm{N}_{2} \mathrm{O}_{\text {ads }}$ and $\mathrm{O}_{\text {ads }}$ on the surface.

Figure 10 shows the $N$ 1s and $O$ 1s $X P$ spectra obtained by dosing NO (3.75 $\times 10^{-6}$ Torr; $\left.30 \mathrm{~min}\right)$ at $80 \mathrm{~K}$ and subsequent warming. The $\mathrm{N} 1 \mathrm{~s}$ core level shows that two types of nitrogen species are produced on the surface. The species with binding energy of $403.5 \mathrm{eV}$ were assigned to molecularly adsorbed $\mathrm{NO}$, and while those with binding energy of $401.5 \mathrm{eV}$ to $\mathrm{N}_{2} \mathrm{O}$. The corresponding $\mathrm{O} 1 \mathrm{~s}$ spectra at $160 \mathrm{~K}$ show a broad peak centered around $532 \mathrm{eV}$ with contribution from $\mathrm{NO}_{\text {ads }}, \mathrm{N}_{2} \mathrm{O}_{\text {ads }}$ and $\mathrm{O}_{\text {ads }}$.

Kruse and co-workers [53] studied the adsorption of $\mathrm{NO}$ on Au 3D hemispherical crystals ("field emitter tips") by means of pulsed field desorption mass spectrometry (PFDMS) under dynamic gas flow conditions and at $300 \mathrm{~K}$. Local chemical probing of Au sites in the stepped surface region between the central (111) pole and the peripheral (001) plane lead to the detection of $\mathrm{NO}^{+}, \mathrm{N}_{2} \mathrm{O}^{+}$and $(\mathrm{NO})_{2}^{+}$ species. No significant amounts of surface oxygen were observed. It was suggested that nitrous oxide formation may occur via the dimer $(\mathrm{NO})_{2}$.

Mullins's group also showed that the NO uptake on the $\mathrm{Au}(111)$ surface is enhanced by the presence of oxygen adatoms, likely due to electronic or structural

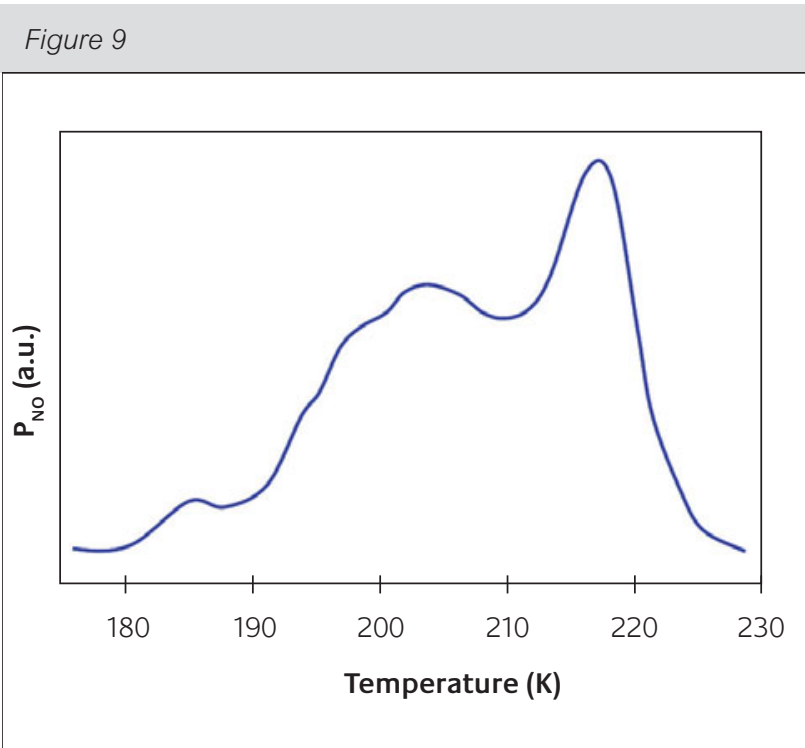

Thermal desorption spectrum after saturation with NO at 170 $\mathrm{K}$ (heating rate is $1 \mathrm{Ks}^{-1}$ ). No desorption signals were obtained after exposure to the same amounts of $\mathrm{CO}$ and $\mathrm{O}_{2}$ (adapted from ref. [42]) 
changes in the Au surface [52]. At temperatures above $200 \mathrm{~K}, \mathrm{NO}_{2}$ production becomes limited by the surface lifetime of the adsorbed NO species. Below $200 \mathrm{~K}$, nitric oxide can react with surface oxygen to form a chemisorbed $\mathrm{NO}_{2}$ product.

Torres et al. [54] used the DFT approach to study the reaction of $\mathrm{NO}$ with atomic $\mathrm{O}$ on the $\mathrm{Au}(111)$ surface at low temperature to form $\mathrm{NO}_{2}$. Very small adsorption energies at fcc and defect sites (19 and $39 \mathrm{kJmol}^{-1}$, respectively) were obtained, implying that the NO adsorption state detected on $\mathrm{Au}(111)$ by McClure et al. [52] at $\sim 175 \mathrm{~K}$ is indeed related to the presence of defects.

Yang and co-workers [22] also used DFT to study $\mathrm{NO}$ adsorption and reaction on clean and atomic oxygen precovered $\mathrm{Au}(111)$ surfaces. While clean
$\mathrm{Au}(111)$ surface is catalytically inert and can only weakly adsorb NO, an atomic oxygen precovered $\mathrm{Au}(111)$ surface is found to be very active to NO. On the clean surface, NO prefers to adsorb on-top surface sites with a tilted geometry. On $0.33 \mathrm{ML}$ (monolayer) oxygen precovered surface $\mathrm{NO}$ reacts with chemisorbed oxygen to form chemisorbed $\mathrm{NO}_{2}$ by conquering a small energy barrier of about 17 $\mathrm{kJmol}^{-1}$, and the desorption energy of $\mathrm{NO}_{2}$ is 62 $\mathrm{kJmol}^{-1}$. On a $1.0 \mathrm{ML}$ oxygen coverage surface, no barrier is found while NO reacts with precovered oxygen. The desorption energy of $\mathrm{NO}_{2}$ is $3 \mathrm{kJmol}^{-1}$. The desorption of $\mathrm{NO}_{2}$ is the rate determining step on both surfaces and the overall reaction barriers are $62 \mathrm{kJmol}^{-1}$ and $3 \mathrm{kJmol}^{-1}$, respectively. The activation energies depend on the initial coverage of oxygen, which compare favorably with experiments on $\mathrm{Au}$ surface with different oxygen coverages.

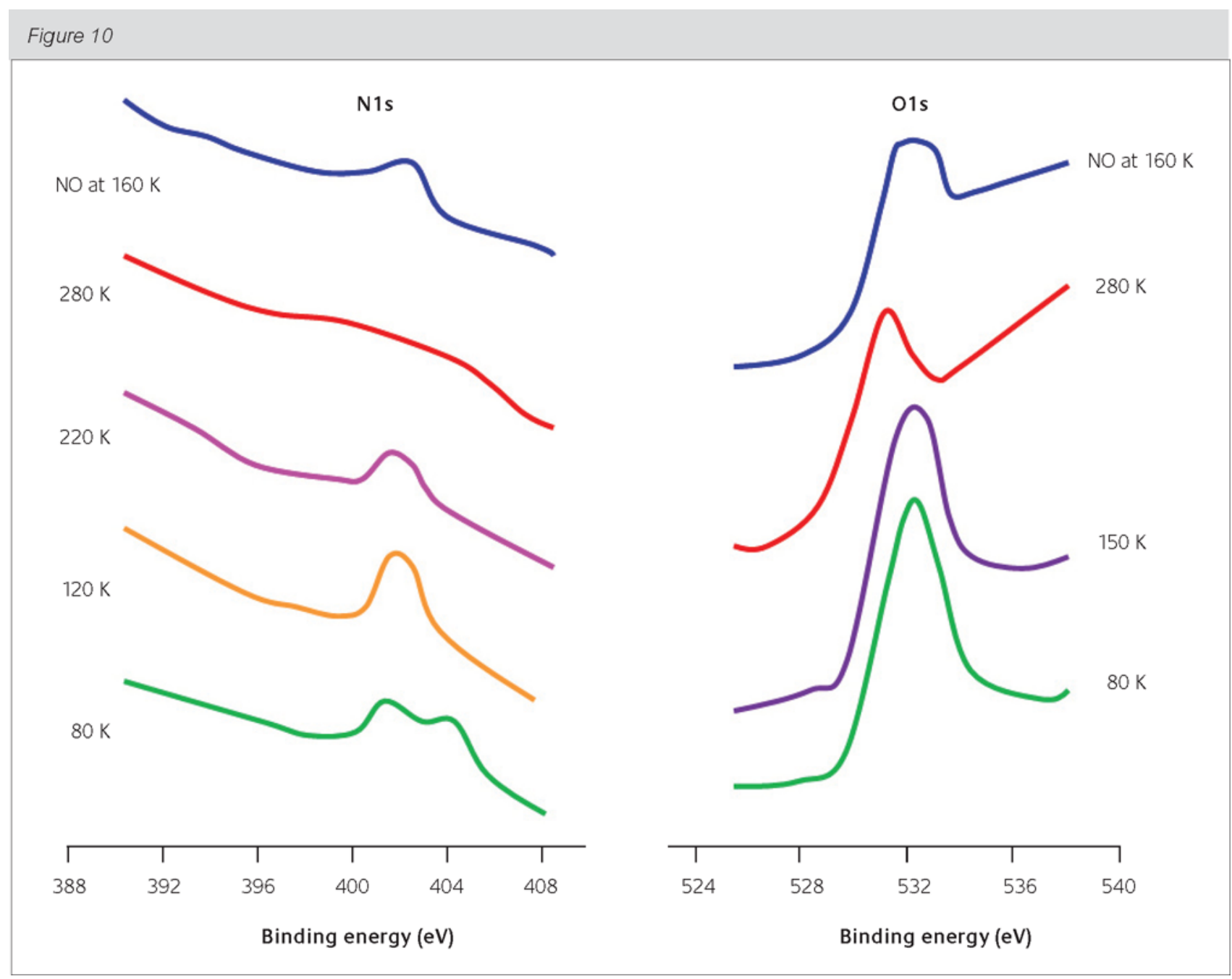

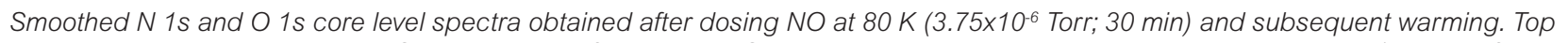
spectra correspond to $\mathrm{N} 1 \mathrm{~s}$ and $\mathrm{O} 1 \mathrm{~s}$ core level after dosing $\mathrm{NO}$ at $160 \mathrm{~K}$ maintaining the same exposure conditions (adapted from ref [18]) 
Hussain et al. [50] used DFT to study NO adsorption on Au(111), (100), (110) and (310) surfaces, as well as on adatoms on $\mathrm{Au}(100)$. The results clearly show that the adsorption energy of the molecules increases considerably with increasing the degree of coordinative unsaturation of the gold atoms to which the molecules bind. These results are consistent with the view that defects, steps and kinks on the surface determine the activity of gold catalysts. The bridge site is favored at low index surfaces but at the stepped (310), top coordination is preferred. In all adsorption configurations, the $\mathrm{N}-\mathrm{O}$ molecular axis is perpendicular to the surfaces except for $\mathrm{Au}(310)$. A tilted geometry with the nitrogen atom almost on top of a gold atom at the edge of the step, while the oxygen atom points towards the next layer of gold atoms belonging to the terrace.

Gomes's group [55] studied NO adsorption and dissociation with and without the presence of hydrogen on the $A u(321)$ surface by DFT and a periodic supercell approach. The calculations show that the molecules prefer to bind on sites near the zigzag steps on this gold surface. Furthermore, the dissociation of molecular hydrogen occurring near the steps of the Au(321) surface has a barrier of $54 \mathrm{kJmol}^{-1}$, a value that is significantly smaller than that calculated for the same reaction on the $\mathrm{Au}(111)$ surface; that is, $109 \mathrm{kJmol}^{-1}$. The calculated energy barrier for $\mathrm{NO}$ dissociation on the clean surface is prohibitively high $\left(336 \mathrm{kJmol}^{-1}\right)$, and the reaction is also too endothermic. The hydrogenation reactions of $\mathrm{NO}$ to $\mathrm{NOH}$ and of $\mathrm{NOH}$ to $\mathrm{NHOH}$ are kinetically and thermodynamically much easier. The energy barriers are 52 and $27 \mathrm{kJmol}^{-1}$, respectively, and the energy of the products is 11 and $-158 \mathrm{kJmol}^{-1}$ when compared with those of the reactants; that is, $\mathrm{NO}+$ $\mathrm{H}$ and $\mathrm{NOH}+\mathrm{H}$, respectively.

Ding et al. [56] studied the adsorption properties of $\mathrm{NO}$ on anionic, cationic, and neutral $\mathrm{Au}_{\mathrm{n}}$ clusters ( $n=1$ to 6 ) using the DFT approach. They found that for adsorption on anionic and cationic clusters, the charge transfer between the Au clusters and NO molecule and the corresponding weakening and elongation of the $\mathrm{N}-\mathrm{O}$ bond are essential factors of the adsorption. The cationic clusters have larger adsorption energies. For neutral $\mathrm{Au}$ clusters, although the charge transfer is small, the adsorption energies are comparable to the anionic cases. According to the authors, all Au clusters with different charge can adsorb $\mathrm{NO}$ molecule, with $\mathrm{Au}_{3}{ }^{-}$ the only exception.
We conclude that just like $\mathrm{CO}, \mathrm{NO}$ is only very weakly adsorbed on $\mathrm{Au}(111)$. On the more open surfaces the adsorption energy is much higher and increases with increasing unsaturation of the gold atoms to which the molecule binds. Interestingly, on some stepped surfaces $\mathrm{NO}$ decomposes to $\mathrm{N}_{2} \mathrm{O}$ and adsorbed $\mathrm{O}$, most probably via a dimer $(\mathrm{NO})_{2}$. Adsorbed $\mathrm{O}$ atoms greatly increases the reactivity of gold surfaces and $\mathrm{NO}_{2}$ is formed.

\section{Adsorption of ammonia, methanol and water. Effect of $\mathbf{O}$}

Liuetal. [57] performed DFT calculations to investigate the adsorption and dehydrogenation of $\mathrm{NH}_{3}$ on the $\mathrm{Au}(111)$ surface. For $\mathrm{NH}_{3}$ the on-top site and for $\mathrm{NH}_{2}$ the bridge site is favoured on this surface, while for $\mathrm{NH}$ the hollow (fcc) site is preferred. The adsorbates are adsorbed on the gold surface with interaction between $p$ orbital of adsorbate and d orbitals of gold. The interaction with the gold surface increases in the order $\mathrm{NH}_{3}<\mathrm{NH}_{2}<\mathrm{NH}<\mathrm{N}$. The dissociation of $\mathrm{NH}_{3}$ was also investigated on the pre-covered oxygen and precovered hydroxyl surface. The results show that the reaction energy barrier for dehydrogenation is lower on the O-pre-covered surface. The adsorbed $\mathrm{O}$ can promote the dehydrogenation of $\mathrm{NH}_{3}$. Additionally, $\mathrm{OH}$ participates in a continuous dehydrogenation reaction, and the reaction energy barrier is the lowest $\left(23 \mathrm{kJmol}^{-1}\right)$. The results indicate that $\mathrm{OH}_{\text {ads }}$ plays a key role in the dehydrogenation on the Au(111) surface.

Mullins and co-workers [58] studied the desorption kinetics of methanol on Au(111) employing TPD and molecular beam reactive scattering. They found that methanol is weakly adsorbed and desorbs molecularly. Three adsorption states, which are assigned to methanol molecules desorbing from the monolayer ( $\beta$ phase), amorphous multilayers ( $\alpha$ phase), and crystallized multilayers ( $\alpha$ phase), have been reported. In the presence of adsorbed atomic oxygen, TPD of adsorbed methanol exhibits desorption of $\mathrm{CH}_{3} \mathrm{OH}, \mathrm{H}_{2} \mathrm{O}, \mathrm{CO}$, and $\mathrm{CO}_{2}$. No other partial oxidation products or hydrogen, formaldehyde, formic acid, or methyl formate have been detected. It was suggested that abstraction of a hydrogen atom is the initial step in the surface decomposition of methanol and that adsorbed methoxy is the primary intermediate in the oxidation of methanol. These results further demonstrate that atomic oxygen precovered gold surfaces can be catalytically active. 
Vinod et al. [59] reported on the adsorption and thermal decomposition of methanol on a $\mathrm{Au}(310)$ surface studied by TP-XPS and TPD. This stepped surface was able to break the $\mathrm{O}-\mathrm{H}$ bond in $\mathrm{CH}_{3} \mathrm{OH}$. Adsorbed $\mathrm{CH}_{3} \mathrm{O}$ (methoxy) species is formed, without the aid of adsorbed oxygen, at $\sim 150 \mathrm{~K}$ (monolayer adsorption) to $200 \mathrm{~K}$ (multilayers) depending on the initial coverage. It was thus found that the sites on the $\mathrm{Au}(310)$ surface in the form of steps and kinks, play a crucial role in the $\mathrm{O}-\mathrm{H}$ bond activation. It was also shown that the $\mathrm{C}-\mathrm{O}$ bond scission is not a favourable process on this surface.

Chen et al. [60] used DFT to study adsorption energies of methanol, methoxy, and formaldehyde, as well as the decomposition pathway of methanol on the Au(111) surface. They found that methanol and formaldehyde have a low adsorption energy. The geometry of adsorbed formaldehyde is similar to that in the gas phase, indicating a physisorption state. Nevertheless, the intermediate methoxy is strongly attached to the metal surface by the $\mathrm{O}$ atom. The possible decomposition pathway for $\mathrm{CH}_{3} \mathrm{OH}$ over $\mathrm{Au}(111)$ surface is: firstly, $\mathrm{O}-\mathrm{H}$ bond breaks to form the intermediate methoxyl radical $\mathrm{CH}_{3} \mathrm{O}$; then $\mathrm{O}-\mathrm{C}$ bond is broken and the $\mathrm{HCHO}$ is formed. The final step is the rate-determining and formaldehyde is the major product of methanol oxidation.

Friend and co-workers [61] investigated the effect of adsorbed oxygen on the hydrogen bonding of water on Au(111). TPD experiments showed two peaks at 175 and $195 \mathrm{~K}$ following exposure to water of the oxygen-covered surface. The peak at $175 \mathrm{~K}$ was ascribed to sublimation of multilayers of water, whereas the peak at $195 \mathrm{~K}$ was associated with oxygen-stabilized water or a water-hydroxyl surface complex. Isotopic exchange of adsorbed $\mathrm{O}^{16}$ with $\mathrm{H}_{2}{ }^{18} \mathrm{O}$ following adsorption and subsequent temperature programmed reaction, however, indicates that transient $\mathrm{OH}$ species are formed. The hydroxyls are short-lived, forming and disproportionating multiple times before water desorption during TPD. Chemisorbed oxygen showed to be critical for the formation of hydroxyls and stabilizing water, whereas gold oxide does not contribute to these effects.

\section{Conclusions}

All the surface science experiments and DFT calculations show that dissociative adsorption of oxygen and hydrogen is a very unlikely process on well defined clean gold surfaces. For CO,
$\mathrm{NO}, \mathrm{NH}_{3}$ and $\mathrm{CH}_{3} \mathrm{OH}$ a large effect of the gold surface structure has been reported. These results demonstrate that low-coordinated gold atoms present on steps and kinks are required for high catalytic activity. The presence of atomic $O$ has a large beneficial effect on the activity of gold surfaces.

\section{Acknowledgements}

SACC is grateful to Fundação para a Ciência e Tecnologia, Portugal, for financing (CIENCIA 2007 program).

\section{About the authors}

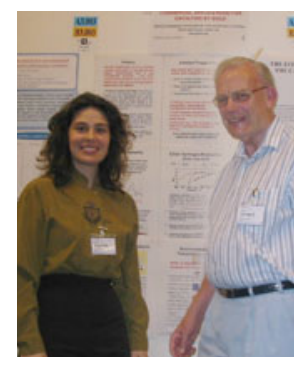

Dr. Sónia A.C. Carabineiro obtained her Ph.D. in Catalysis at the New University of Lisbon, Portugal. She was a post doc at Leiden University, The Netherlands, working with Ben Nieuwenhuys, where she met David Thompson. She had just written a paper for the Dutch magazine "Chemisch Weekblad" on "The golden future of gold catalysts". David was an enthusiastic promoter of catalysis by gold, and they became good friends. She returned to Portugal and after another post-doc position at the Technical University of Lisbon, she moved to the University of Porto as an assistant researcher. In the meantime, Sónia was a co-author of two book chapters with David and is currently working in the field of gold catalysed oxidation reactions.

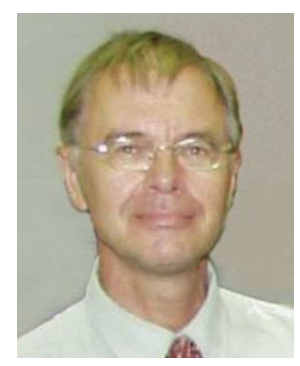

\section{Prof. Bernard E. Nieuwenhuys} received his Ph.D. in Chemistry from the Leiden University, the Netherlands, under the tutelage of W.M.H. Sachtler. Between 1975 and 1976 he was a postdoctoral fellow at the University of California, Berkeley, where he worked under the supervision of G.A. Somorjai. In 1977 he joined the Faculty of Chemistry at the Leiden University. He is a professor in heterogeneous catalysis and surface chemistry, also part-time at the Eindhoven University of Technology, the Netherlands. 


\section{References}

1 C.W. Corti and R.J. Holliday, Gold Bull., 2004, 37, 20

2 C.W. Corti, R.J. Holliday and D.T. Thompson, Appl. Catal. $B, 2005,291,253$

3 G.C. Bond, C. Louis and D.T. Thompson, Catalysis by Gold. Catalytic Science Series, ed. G.J. Hutchings. Vol. 6. 2006, London, United Kingdom: Imperial College Press

4 C.W. Corti, R.J. Holliday and D.T. Thompson, Top. Catal., 2007, 44, 331

5 S.A.C. Carabineiro and D.T. Thompson, Catalytic Applications for Gold Nanotechnology, in Nanocatalysis, E.U. Heiz and U. Landman, Editors. 2007, Springer-Verlag: Berlin, Heidelberg, New York. p. 377

6 R. Meyer, C. Lemire, S.K. Shaikhutdinov and H. Freund, Gold Bull., 2004, 37, 72

7 S.A.C. Carabineiro and B.E. Nieuwenhuys, Gold Bull., 2009, in preparation

8 J.L. Gong and C.B. Mullins, Acc. Chem. Res., 2009, 42, 1063

9 B.K. Min and C.M. Friend, Chem. Rev., 2007, 107, 2709

10 Available from: http://www.fhi-berlin.mpg.de/ hermann/ Balsac/SSDpictures.html\#A

11 B.K. Min, A.R. Alemozafar, M.M. Biener, J. Biener and C.M. Friend, Top. Catal., 2005, 36, 77

12 K.D. Gibson and S.J. Sibener, J. Phys. Chem. A, 2007, 111, 12398

13 B.K. Min, X. Deng, D. Pinnaduwage, R. Schalek and C.M. Friend, Physical Review B, 2005, 72, 121410

14 J. Kim, E. Samano and B.E. Koel, Surf. Sci., 2006, 600, 4622

15 M. Mavrikakis, P. Stoltze and J.K. Norskov, Catal. Lett., 2000, 65, 101

16 Available from: http://w3.rz-berlin.mpg.de/ rammer/ surfexp_prod/SXinput.html

17 I. Nakamura, A. Takahashi and T. Fujitani, Catal. Lett., 2009, 129, 400

18 C.P. Vinod, J.W.N. Hans and B.E. Nieuwenhuys, Appl. Catal. A, 2005, 291, 93

19 T.A. Baker, C.M. Friend and E. Kaxiras, J. Chem. Phys., 2009, 130, 084701

20 T.A. Baker, C.M. Friend and E. Kaxiras, J. Phys. Chem. C, 2009, 113, 3232

21 Z.H. Zeng, H.Q. Deng, W.X. Li and W.Y. Hu, Wuli Xuebao/ Acta Physica Sinica, 2006, 55, 3157

22 W.H. Zhang, Z.Y. Li, Y. Luo and J.L. Yang, J. Chem. Phys., 2008, 129, 134708

23 E. German and I. Efremenko, Journal of Molecular Structure-Theochem, 2004, 711, 159

24 N. Saliba, D.H. Parker and B.E. Koel, Surf. Sci., 1998, 410 270

25 H. Shi and C. Stampfl, Physical Review B, 2007, 76, 075327

26 D. Torres, K.M. Neyman and F. Illas, Chem. Phys. Lett., 2006, 429, 86

27 S.D. Miller and J.R. Kitchin, Mol. Simul., 2009, 35, 920

28 S.D. Miller and J.R. Kitchin, Surf. Sci., 2009, 603, 794
29 M. Landmann, E. Rauls and W.G. Schmidt, Physical Review B, 2009, 79, 045412

30 M. Landmann, E. Rauls and W.G. Schmidt, J. Phys. Chem. C, 2009, 113, 5690

31 J.L.C. Fajin, M. Cordeiro and J.R.B. Gomes, J. Phys. Chem. C, 2007, 111, 17311

32 J.L.C. Fajin, M. Cordeiro and J.R.B. Gomes, Surf. Sci., 2008, 602, 424

33 Y. Okamoto, Chem. Phys. Lett., 2005, 405, 79

34 E.M. Fernández, P. Ordejón and L.C. Balbás, Chem. Phys. Lett., 2005, 408, 252

35 L.M. Molina and B. Hammer, J. Chem. Phys., 2005, 123, 161104

36 L. Barrio, P. Liu, J.A. Rodriguez, J.M. Campos-Martin and J.L.G. Fierro, J. Phys. Chem. C, 2007, 111, 19001

37 J.M. Gottfried, K.J. Schmidt, S.L.M. Schroeder and K. Christmann, Surf. Sci., 2003, 536, 206

38 J. Kim, E. Samano and B.E. Koel, J. Phys. Chem. B, 2006, 110, 17512

39 C.J. Weststrate, E. Lundgren, J.N. Andersen, E.D.L. Rienks, A.C. Gluhoi, J.W. Bakker, I.M.N. Groot and B.E. Nieuwenhuys, Surf. Sci., 2009, 603, 2152

40 L. Piccolo, D. Loffreda, F. Aires, C. Deranlot, Y. Jugnet, P. Sautet and J.C. Bertolini, Surf. Sci., 2004, 566-568, 995

41 M.S. Pierce, K.C. Chang, D.C. Hennessy, V. Komanicky, A. Menzel and H. You, J. Phys. Chem. C, 2008, 112, 2231

42 E.D.L. Rienks, G.P. Van Berkel, J.W. Bakker and B.E. Nieuwenhuys, Surf. Sci., 2004, 571, 187

43 F.J. Cadete Santos Aires, M.-A. Languillea, Y. Jugnet and J.C. Bertolini, The evolution of Au (110) surface structure induced by $\mathrm{CO}$ adsorption by in situ environmental STM study (from 10-9 to 500 Torr), in Gold 2009 - The 5th international conference on gold science, technology and its applications, 2009, Heidelberg, Germany

44 Y. Jugnet, F. Aires, C. Deranlot, L. Piccolo and J.C. Bertolini, Surf. Sci., 2002, 521, L639

45 W.L. Yim, T. Nowitzki, M. Necke, H. Schnars, P. Nickut, J. Biener, M.M. Biener, V. Zielasek, K. Al-Shamery, T. Kluner and M. Baumer, J. Phys. Chem. C, 2007, 111, 445

46 P. Maksymovych and J.T. Yates, Chem. Phys. Lett., 2006, 421, 473

47 D. Loffreda and P. Sautet, J. Phys. Chem. B, 2005, 109, 9596

48 D. Loffreda, L. Piccolo and P. Sautet, Physical Review B, 2005, 71, 113414

49 F. Mehmood, A. Kara, T.S. Rahman and C.R. Henry, Physical Review B, 2009, 79, 075422

50 A. Hussain, D. Curulla Ferré, J. Gracia, B.E. Nieuwenhuys and J.W. Niemantsverdriet, Surf. Sci., 2009, 603, 2734

51 M.E. Bartram and B.E. Koel, Surf. Sci., 1989, 213, 137

52 S.M. Mcclure, T.S. Kim, J.D. Stiehl, P.L. Tanaka and C.B. Mullins, J. Phys. Chem. B, 2004, 108, 17952

53 T.D. Chau, T.V. De Bocarme and N. Kruse, Catal. Lett., 2004, 98, 85 
54 D. Torres, S. González, K.M. Neyman and F. Illas, Chem. Phys. Lett., 2006, 422, 412

55 J.L.C. Fajin, M. Cordeiro and J.R.B. Gomes, J. Phys. Chem. C, 2009, 113, 8864

56 X.L. Ding, Z.Y. Li, J.L. Yang, J.G. Hou and Q.S. Zhu, J. Chem. Phys., 2004, 121, 2558

57 R. Liu, W. Shen, J. Zhang and M. Li, Appl. Surf. Sci., 2008, 254, 5706
58 J. Gong, D.W. Flaherty, R.A. Ojifinni, J.M. White and C.B. Mullins, J. Phys. Chem. C, 2008, 112, 5501

59 C.P. Vinod, J.W. Niemantsverdriet and B.E. Nieuwenhuys, Phys. Chem. Chem. Phys., 2005, 7, 1824

60 W.K. Chen, S.H. Liu, M.J. Cao, Q.G. Yan and C.H. Lu, Journal of Molecular Structure-Theochem, 2006, 770, 87

61 R.G. Quiller, T.A. Baker, X. Deng, M.E. Colling, B.K. Min and C.M. Friend, J. Chem. Phys., 2008, 129, 064702 